\title{
8. Collaborative reform: lessons from the COAG Reform Council, 2008-2010
}

\author{
Mary Ann O'Loughlin
}

During the 2007 federal election campaign, Kevin Rudd pledged to reform Commonwealth-state relations if elected - an unusual mandate to request, given that Commonwealth-state relations have rarely garnered much community interest. ${ }^{1}$ But Rudd was very experienced in this field, having worked in both the Commonwealth Public Service and the Queensland Public Service, as well as serving as chief of staff to former Queensland Premier Wayne Goss. In the lead-up to the election, Rudd promised to 'end the blame game', with a primary focus on health. This message resonated with the community, allowing Rudd to take a reform agenda for Commonwealth-state relations into office.

The Labor Government was elected in November 2007 and Rudd held his first Council of Australian Governments (COAG) meeting in December. The meeting agreed 'to a new model of cooperation' and identified seven areas of reform for its 2008 work agenda. COAG also agreed to change the nature of Commonwealthstate funding arrangements, with treasurers to report on proposed reforms. To drive reforms, COAG agreed to meet four times in 2008.

\section{Reforming federal financial relations}

The COAG meeting of November 2008 welcomed a 'new era in federal financial relations', with the Intergovernmental Agreement on Federal Financial Relations coming into effect on 1 January 2009. There are three main elements of the new financial arrangements

1. National Specific Purpose Payments supported by new National Agreements

2. National Partnership payments associated with National Partnership Agreements

3. a performance and assessment framework to support public reporting and accountability.

1 References to the 'state' or 'states' include the state governments and territory governments. 


\section{National Specific Purpose Payments and National Agreements}

Under the new framework for federal financial relations, the previous more than 90 different payments from the Commonwealth to the states for specific purposes - many containing prescriptive conditions on how the funding should be spent - have been combined into five new National Specific Purpose Payments. National Specific Purpose Payments are ongoing financial contributions from the Commonwealth to the states to be spent in the key service-delivery sectors of schools, skills and workforce development, health care, affordable housing, and disability services. The states are required to spend each National Specific Purpose Payment in the service sector relevant to the payment but they have full budget flexibility to allocate funds within that sector as they see fit to achieve the agreed objectives for that sector.

National Specific Purpose Payments are associated with National Agreements between the Commonwealth and state governments. National Agreements establish the policy objectives in the service sectors of education, skills and workforce development, health care, affordable housing, and disability services. There is also a National Agreement on Indigenous Reform, which does not have an associated Specific Purpose Payment, although it links to other National Agreements and National Partnerships, which have associated funding.

National Agreements set out the objectives, outcomes, outputs and performance indicators for each sector, which are agreed between all jurisdictions. The agreements also aim to clarify the roles and responsibilities of the Commonwealth and states in the delivery of services and the achievement of outcomes. They do not include financial or other input controls imposed on service delivery by the states, and there is no provision for National Specific Purpose Payments to be withheld in the case of a jurisdiction not meeting a performance benchmark specified in a National Agreement.

\section{National Partnership Agreements and payments}

National Partnership Agreements outline agreed policy objectives in areas of nationally significant reform or for service-delivery improvements, and define the outputs and performance benchmarks. They cover a wide range of service sectors and reform areas, from health, education and housing through to business regulation and competition. National Partnership Agreements differ from National Agreements in that generally they are time limited and the associated National Partnership payments for the states are linked with specific reform activities or projects. The Commonwealth provides National Partnership payments for three purposes: to support the delivery of specified projects, to facilitate reforms, or to reward those jurisdictions that deliver on nationally significant reforms. 


\section{Performance and assessment framework}

The third main element of the new federal financial relations arrangements is a performance and assessment framework to support public reporting and accountability. Under the Intergovernmental Agreement, the Commonwealth and states have agreed to greater accountability through simpler, standardised and more transparent performance reporting, and 'a rigorous focus on the achievement of outcomes - that is, mutual agreement on what objectives, outcomes and outputs improve the well-being of Australians' (COAG 2008).

\section{Devolution and transparency}

The remainder of this chapter looks more closely at COAG's collaborative reform of federal financial relations. It uses a framework put forward by Michael Barber, the expert partner in McKinsey's Global Public Sector Practice, who was previously head of former UK Prime Minister Tony Blair's delivery unit. Barber identifies three paradigms of public-sector reform

- command and control - top-down management

- devolution and transparency-devolution of responsibility, public accountability for results to drive performance, and incentives to encourage improved performance

- using markets and quasi-markets - including privatisation and contracting out.

COAG's reform of federal financial relations is a good example of the devolution and transparency paradigm

- responsibility is devolved - in this case from the Commonwealth to the states

- there is a strong accountability framework, with the COAG Reform Council responsible for public reporting of the performance of governments

- there is a range of incentives to drive performance, particularly public accountability under the National Agreements and financial rewards for the achievement of benchmarks and milestones under a number of National Partnerships.

For all paradigms of public-sector reform, Barber argues that there are three underlying requirements for effective reform: strategic direction, performance management, and the three Cs-capability, capacity and culture. 


\section{Strategic direction: focus from research and dialogue}

Barber argues that a sustained, well-thought-through strategy is needed to guide reform. The COAG reforms of 2008 had the advantage of being guided by a strong sense of strategic direction. This was true both for the policy agenda in the areas of productivity, human capital and competition and regulation, and for the reform of the architecture of federal financial relations.

Much work had been done in 2005-06 to develop what was then called the National Reform Agenda for COAG. This agenda focused on human capital, competition and regulatory reform streams. The COAG reform agenda of 2008 built on this previous work.

In the area of federal financial relations, the strategic direction guiding the reforms was the outcome of a long process of research, consultation and debate. Although Kevin Rudd brought the issue of federalism reform to the fore in 2007, there had long been discussion and debate around the issues, informed by academic research into the problems with our federal financial relationshipsparticularly the problems of the overlapping roles and responsibilities of the Commonwealth and the state governments, and of vertical fiscal imbalance.

In a speech given in November 2009, Terry Moran, Secretary of the Department of Prime Minister and Cabinet, himself a strong advocate for the Commonwealthstate reforms, described the intensive work involved, and the resulting new arrangements. He said the reform process was:

Long and painful; I played a role in Victoria and then at the Commonwealth level. Hear me when I say that the states and territories got what they had campaigned for. That includes a new basis for financial relations - 96 Specific Purpose Payments reduced to six, saving the states and territories from much micro-management. It includes a new basis for accountability - agreed objectives, strategic outcomes, outputs and measures to guide these new streams of money and free the states to innovate in health, schools, vocational education and training, housing, Indigenous matters and other areas...And it includes a new independent umpire - the COAG Reform Council-to assess the performance of governments against the goals of the COAG reform agenda. (Moran 2009)

Moran's insight demonstrates that when the appropriate research and development work are conducted, a clear strategic direction for the reform can follow. 


\section{Performance management: moving to a new level}

The second factor underpinning public-sector reform identified by Barber is performance management. This is where we at the COAG Reform Council come in. The council is central to the new accountability arrangements. The Intergovernmental Agreement gives the council significant responsibilities for assessment and reporting of the performance of governments under National Agreements and National Partnerships.

For each of the six National Agreements, the COAG Reform Council provides annual reports to COAG based on a comparative analysis of the performance of governments against agreed indicators. The first-year reports establish benchmarks against which progress in reform and improvements in service delivery can be measured.

For National Agreements, the Reform Council's performance-review process is a fairly intense exercise. The performance information for each National Agreement is received from the Steering Committee for the Review of Government Service Provision. The council's report on the National Agreement is due to COAG within three months of receiving the data, and the council must formally consult with the jurisdictions on the report during this three-month period.

The COAG Reform Council's main accountability role for National Partnerships is to independently assess whether performance benchmarks or milestones have been achieved before the Commonwealth makes reward payments to the states. As of November 2010, there were seven National Partnerships with reward payments agreed by all jurisdictions: six reward National Partnerships in health and education, and the National Partnership Agreement to Deliver a Seamless National Economy, which has 36 streams of regulation and competition reform. The council publicly releases all its reports about a month after submitting them to COAG; they are available on our web site $(<w w w$. coagreformcouncil. gov.au>).

Effective performance management depends on being able to measure results and change. This is acknowledged in the Intergovernmental Agreement, which notes that the success of the new framework for federal financial relations depends crucially on the development of robust performance indicators and benchmarks' (COAG 2008). A significant challenge for the council in undertaking its accountability role is the availability of performance indicators that are meaningful, simple and comprehensive for members of the public, as well as robust data to support these indicators and allow for analysis of change over time. After all, a key purpose of performance monitoring and reporting is to inform the general public about government performance and overall progress. 
In its first-year reports to COAG on the National Agreements, the council highlighted the many problems with data and performance indicators that were hindering effective performance reporting. For example, the National Healthcare Agreement is a very complex agreement with 15 output measures, 20 progress measures and 70 performance indicators. For the baseline report, data were available only for 58 indicators in a comparable form. Many of the indicators are output rather than outcome measures. There are also no quality and safety measures, measures of patient satisfaction, or data on the extent to which the services are actually meeting need. The council has identified similar types of problems - although not on such a scale — with all the National Agreements.

The good news is that COAG, at its December 2009 meeting, requested the heads of treasuries to undertake a review of National Agreements and National Partnerships, covering the clarity and transparency of objectives and outcomes and roles and responsibilities, and the quantity and quality of performance indicators and benchmarks. The report was submitted to COAG at the end of 2010. We look forward to seeing the results of this work.

\section{Reform culture: focusing on outcomes and performance}

Barber's third underpinning for effective public-sector reform comprises three interrelated challenges when effecting change: capability, capacity and culture. Here I will focus on culture. The late management consultant Peter Drucker once famously said 'culture eats strategy for breakfast'. In other words, while strategic direction and performance management are important ingredients for effective reform, if the necessary culture for change is not in place, the reform agenda will not be achieved. There are two key points to be made here.

First, significant cultural shifts are necessary to ensure public servants - at both the Commonwealth and the state level-move from an input-orientated focus to an outcome-orientated one. This requires a new way of thinking, planning and measuring, and can thus be difficult to adopt. It is much easier and more comfortable to measure inputs (for example, the level of funding) than outcomes (for example, what results are being achieved with the funding). There is a risk that people will revert to command-and-control input measurement if outcome measurement proves too difficult. Strong leadership at the Commonwealth and state levels is essential to direct and support the necessary cultural change.

Second, we must move away from a culture that equates accountability simply with sanctions and punishment, be it by supervisors, the media or interest groups. Greater transparency in public accountability for governments' performance is a potentially significant achievement of COAG's reform agenda. 
But it is essential that those whom we want to hold accountable have a clear understanding of what accountability means. Accountability should encompass not just monitoring, feedback and reporting, but also the extent to which governments are allowed the opportunity to act constructively on feedback about their own performance.

\section{Concluding remarks}

According to the contribution in this volume by Aart de Geus, Deputy SecretaryGeneral of the Organisation for Economic Cooperation and Development (OECD), the confluence of two factors is necessary for significant reform: a broad-based popular sentiment that things have to change; and leadership that is able to translate this broad dissatisfaction into concrete reform proposals. Both these factors are often difficult to achieve, but the degree of difficulty increases with collaborative reform.

In Australia, collaborative reform involves nine jurisdictions, requiring the engagement of nine sets of popular sentiments and the commitment of nine frequently changing political and bureaucratic leaderships. And while Kevin Rudd garnered much public support for ending the 'blame game' during the 2007 election campaign, this support was focused on improving service delivery rather than identifying institutional requirements to do so. Additionally, it is difficult to build an evidence base around institutional reform, so it is harder to make the arguments and gather support for reform. For many reasons, popular support can be difficult to mobilise for what can seem like the arcane topic of reform of federal financial relations.

Regarding leadership, there are many associated issues that make collaborative reform difficult. First, the nature of our federation and form of government can pit Commonwealth leaders against state leaders; prime ministers, treasurers and premiers against line ministers; and, at the bureaucratic level, central agencies against line agencies. These key players often face very different pressures, including from interest groups.

In the public sector, we are also faced with the problem of the reformer bearing the brunt of the reform. In effect, we are asking public servants to design and implement their own reform, imposing measures on themselves that might significantly impact on how they have done their business in the past. This can result in a loss of power as the power shifts somewhere else.

These are interesting times for collaborative reform in Australia. As Julia Gillard begins her first term as elected Prime Minister, what can we expect her approach to be towards what Terry Moran calls 'the bold experiment'? Moran's view on 
the current exercise in collaborative reform is that if we do not see improved outcomes for Australians in service delivery then the opportunity will be lost and the future direction of the federation will change. On the positive side, there has been great progress in a short time through political and bureaucratic leadership at all levels - through the Commonwealth and states, across central and line agencies, through commitment and persistence, hard thinking and hard work. There is definitely momentum. The view of the COAG Reform Council is that the challenge is to stay the course and gain the benefits.

In his book The Intelligence of Democracy, Charles E. Lindblom argues that democracy is superior to other political systems because of the greater number of incentives to encourage intelligence and learning in the process of policy making. If this is indeed the case then the greatest opportunity for intelligent policy making across a federation of nine jurisdictions is to be achieved through collaboration with, and learning from, one another.

\section{References}

Council of Australian Governments (COAG) 2008, Intergovernmental Agreement on Federal Financial Relations, Council of Australian Governments, Canberra.

Lindblom, C. E. 1965, The Intelligence of Democracy, Free Press, New York.

Moran, T. 2009, Speech delivered at the Don Dunstan Oration, Institute of Public Administration Australia, Adelaide, 6 November 2009. 